\title{
Study on Population Changes of Important Sucking - Pests (Aphis Gossypii (Glov.) and Bemisia Tabaci (G.) in the New Varieties Second Plant (After Canola) in the Golestan Province of Iran.
}

Taghi Darvish, Mojeni ( $\nabla$ t_mojeni@yahoo.com )

Cotton Research Institute

Mohammadreza Zangi

Cotton Research Institute

Research

Keywords: Cotton variety, Sucking - pests, Golestan province

Posted Date: June 21st, 2021

DOl: https://doi.org/10.21203/rs.3.rs-585098/v1

License: (c) (1) This work is licensed under a Creative Commons Attribution 4.0 International License.

Read Full License 


\section{Abstract}

Investigating the population dynamic of important cotton pests on new cotton varieties is important. Cotton cultivars have important pests such as thrips, aphids, whitefly and bollworm. Considering the premature cultivars with proper yield for second cultivation in cotton-growing Golestan province at the north of Iran, this study seems necessary. This genotypes was cultivated with 9 treatments in 4 replicates. A completely randomized block design was carried out in Hashem Abad research station in a spray-free plot with the dimensions of $30 \times 80 \mathrm{~cm}$ in 2018-2019 years. According to the results of this study, analysis of variance of two years showed that the yield of N2G80 with $1538 \mathrm{~g}$ in the plot with $41.7 \%$ lint percentage had the highest yield, and M13 with $685 \mathrm{~g}$ in the plot and $35.8 \%$ lint percentage in the lowest yield they had.The infestation rate of the genotypes tested in the population of green aphid of cotton in K880-2 and Golestan ${ }^{\circledR}$ cultivars was 48.88 and 40.31 in aphid with the highest density, and the SKT-133 and TBL-60 genotype respectively with 27.15 and 29.11 aphids per leaf had the least infestation. The amount of infestation of the genotypes tested to the population of whitefly cotton on the N2G80 and TBL-60 genotype was 90.76 and 68.86 whitefly in the leaf with the highest infestation and N2G80 and TBL-60 genotype respectively with 40.05 and 75.51 white fly in leaf were the least infested. Correlation coefficient between traits was equal to 0.55 . The number of bolls per plant was not correlated with other traits including boll weight, lint percentage, aphid and white fly.

\section{Introduction:}

More than 200,000 hectares of land annually are allocated to cotton cultivation in Iran. Cotton cultivars have important pests such as thrips, aphids, whitefly and bollworm. Changes in the population of major cotton pests in Golestan province were shown on new cultivars in cotton regions of the country relative to normal cropping in the region that cultivars tolerant to the most important pests of sepid cotton had the lowest infection with bell worm and sucker pests (aphids and white fly) in the Golestan province region. (Darvish,Mojeni,1994,1996 and 1996). A study was conducted on the cultivars tolerant to cotton aphid in Hashemabad station. Akala.S.J $\times$ ciland-2 variety has the lowest infection with cotton aphid and other cultivars, such as Zeta - 2, 010, Bakhtegan and Bulghar 433, had moderate infestation (Darvish, Mojeni, 2000). Pest activity of cotton in the region with two important peaks in early June in early June and early July in Gorgan and Gonbad (Darvish, Mojeni ,2006).

White fly is one of the most important pests of Golestan province that started its activity in late July due to its favorable weather conditions and is observed at the end of crop season with considerable density. The infestation rate of different cotton varieties in cotton honey showed that the cultivar sepid has the lowest infestation with cotton white fly due to low leaf area and low cracking compared to other cultivars(Abaei and Darvish, Mojeni 1994). The infestation rate of different cotton varieties in cotton Liriomyza trifolli in Golestan province showed that Sahel, tobladyla, Sindoz and B-557 have the highest population of Liriomyza trifolli and Hashem Abad indigenous, native red leaves, Frigo brakte and siokra have the smallest population of leaf miner (Darvish Mojeni and Alishah, 2006 and 2013). In order to clarify the changes in the population of major cotton pests in the second crop on four cultivars (43259, 
43347, B-557 and sahel) at Hashem Abad research stations of Gorgan and Kordkoy in a spray-free plot of $40 \times 50$ square meters, according to the traditions of the area, were cultivated in each other during the second half of June of the year 2005-2006. The results showed that B-557 and 43259 cultivars compared to the average population of important sucking pests such as Aphis gossypii (Glov.) and green hopper Asymmtraca decdens (Dlabo.) and Thrips tabaci (L.) and cotton white fly Bemisia tabaci (G.) compared to the Sahel (check) and other cultivars were lowest infestation(Darvish, Mojeni, 2009). In researches on the rate of infestaion of successful cotton lines to the important sucking pest lines Tbl-180, N2G80, Skt-133 and Skt-134 have shown the least infestation compared to the typical cultivar of the region of Golestan province. Infestation of new hybrids to the populations of important sucking pests in Golestan province, Skt-134, Tbl-80 and N2G80 hybrids had the least infestation with the populations of important sucking pests such as thrips, aphids, white fly (Darvish, Mojeni, 2012 and 2013). Sirjani and Montazeri, in 2012, on tolerant cotton cultivars have been studying Bemisia tabaci cotton in Kashmar it was stated that Varamin cultivar had a mean density of 23.4 nymphs and $11.2 \%$ of full insects in leaf and the highest Nazli variety was 84 with an average of 11.5 nymphs and 8.6 the lowest infestation in white fly cotton. Sirjani and Ramezani Moghadam in 2012 studied the difference in infestation of 7 cotton cultivars with Creonids pallidus cotton in Kashmar and results showed that cultivar 43200 with an average of 5.35 insects per plant and Irma cultivar with an average of 1.93 insects per plant had the highest and lowest population density of Creonids pallidus. Sirjani in 2012 compared the results of 7 cotton cultivars in terms of infestation with Empoasca decipiens cotton in Kashmar that khordad cultivars with the average of 56.5 insects per leaf had the highest infestation and Superokrera cultivar with an average of 2.86 insects per leaf had the least infestation. In the Philippine Research Institute (C R D I), 30 varieties and cotton lines were used for cotton aphid resistant cultivars and reported 5 resistant cultivars. Among other cultivars, 17 varieties showed a low resistance, six cultivars were susceptible and the remaining two cultivars showed high susceptibility to aphid damage (Susa, et al.,1997). Several cotton cultivars and lines in Pakistani province were examined for morphological characteristics related to pest resistance and it came to the conclusion that the earliness in the cultivars makes it possible to flee from the end of the season's white fly and bollworm (Kumar and Saini, 2008). An investigation has been conducted on the economic threshold of aphid control and tolerance of the cotton plant to the aphid (Gao, 1989). In India, the cotton white fly population dynamic with the use of sticky yellow traps for pest prevention (Nandihalli, et al., 1993 ). In India, studies on eleven varieties of Gossypium arboreum, $G$. hirsutum, $G$. haerbaceum cotton species have been performed to determine the aphid tolerant variety and state that according to the morphological and anatomical analysis of cotton plants, the varieties that are cortical and also the leaves with thick parenchyma and the distance between the barrows at the lower level of the leaf is important for feeding the pest. Therefore, the aphid activity on the varieties with these characteristics is more than the varieties that have no sting or dense sting at the plant's puberty at the leaf surface (Khan and Agarwal, 1990). Studying on the preference of cotton-green aphids on six cotton cultivars in Greece in 2006. The results showed that Eva cultivar had a high trichome density on leaf with a population of 58-62 aphids in leaf and the Zeta-2 cultivar had the lowest aphid population with the lowest trichome density on the leaf of aphid, 29-33 aphids in leaf of the least aphid population (Kosas, et al., 2006). 
The genotypes RS2098, CNH911, and PA183 were non-preferred for oviposition and exhibited an antixenosis mechanism of resistance in cotton to whitefly. The genotypes NHH44, LK861, Supriya, RS2013 and LD694 were categorized as moderately resistant in cotton to whitefly.(Jindal and Dhaliwal,2011)

The genotype $\mathrm{CCH}-4474$ demonstrated tolerance mechanism to whiteflies with less reduction in the plant height $(20.77 \%)$, number of internodes $(15.27 \%)$ and chlorophyll content $(13.44 \%)$ over the control. The high level of resistance in the genotypes LRA-5166 and LHDP-1 can serve as the basis for the genetic improvement of cotton focusing on the development of $B$. tabaci resistant varieties (Tamilselvan, et al.,2020).

\section{Material And Methods:}

The following methods were implemented to achieve the objectives of the project on 2018-2019 year. 1Selection of isolated Piece in Area of $30 \times 80 \mathrm{~m} 2$ for 9 new Cotton early cultivars was cultivated in the second half of June in Golestan Province. There was no spraying in the experimental farm. 2-This experiment was carried out with 9 treatments in 4 replicates in a randomized complete block design. The cultivars in each plot consisted of 6 rows of 11 meters long cotton, $80 \mathrm{~cm}$ row spacing, $20 \mathrm{~cm}$ spacing plant and 2 meters of repetition intervals. This experiment has a total of 36 experimental plots and sampling survey of 4 middle lines of cultivation.3-Sampling: with regular weekly visited, a test piece on each line was randomly placed on 10 cotton plants of 3 leaves, total 30 leaves for sucking pest (aphids,

white fly and thrips) and the various stages of its pests were recorded and recognized in special tables. 4The results were analyzed using MSTATC computer program and the mean of different traits were grouped using Duncan's multiple range test method at $5 \%$ level.

\section{Results:}

Based on studies carried out over a two-year trial and by statistical analysis, data conversion and composite variance analysis was performed using Mstatc software. In terms of the average cotton yield, the highest yield (1538 gr / plot) and M13 (35.8\% lint percentage in the lowest yield) (685 gr / plot) in the two years of N2G80 cultivars with 41.7\% lint percentage) other genotypes included SKT133 (32.6\%), GT40 (32.9\%), TBL60 (35.6\%), K880-1 (37.7\%), Golestan® (33.3\%), and the highest lint percentage were in a group. In terms of average boll weights in tested treatments, the combined variance analysis of two years was N2G80 with $176.3 \mathrm{~g}$ and M13 was the most light weight boll with $138.6 \mathrm{~g}$. Early maturity in the GT40 genotype was $91.3 \%$. While the SKT133 genotype was $34.3 \%$ (Table 1,2 ).

There was a significant difference between the mean of infestation to the population of green aphid in tested treatments with compound analysis of variance during two years of experiment. In SKT-133 and TBL-60 cultivars there were 27.15 and 29.11, respectively, in aphid with the least aphid and K880-2 cultivars and Golestan cultivar had the highest population with 48.85 and 46.31 aphid/leaf, respectively (Table 3). There was a significant difference between the treatments in terms of the average infestation 
rate of white fly cotton in the treatments with combined analysis of variance during two years of experiment. The N2G80 and TBL-60 cultivars with 40.05 and 51.18, respectively, were lowest white fly in the leaf and the BKW30 and K880-2 cultivars were 90.76 and 68.86, respectively, in the leaves with the highest white fly (Table 3,Fig. 2).

Correlation coefficient between traits was equal to 0.55 . The number of bolls per plant was not correlated with other traits including boll weight, lint percentage, aphid and white fly. The correlation between the number of bolls and prematurely was very small and equal to 0.08 . The correlation coefficient of the weight of the boll with lint percentage was 0.68 . The population was positively correlated with the white fly (0.47). The correlation between aphid and white fly was positive and negative $(-0.62)$. There was a positive correlation between the populations of the aphid and the yield of 0.50 . Between the yield value and the early mature correlation, equal was 0.21 (Table 4 ).

Table 1- Analysis of variance of morphological characteristics in cotton genotypes in the second crop (after canola)

\begin{tabular}{|lllllll|}
\hline $\begin{array}{l}\text { Early } \\
\text { maturity }\end{array}$ & Yield (gr/plot) & $\begin{array}{l}\text { Lint } \\
\text { percentage }\end{array}$ & $\begin{array}{l}\text { s.s } \\
\text { Weight of } 30 \\
\text { boll(gr) }\end{array}$ & No.boll & df & $\begin{array}{l}\text { Source } \\
\text { of } \\
\text { changes }\end{array}$ \\
\hline $366.791^{*}$ & $246163.259 *$ & $13.815^{\star *}$ & $168.547^{*}$ & $33.584^{*}$ & 3 & Rep. \\
\hline $1157.515^{\star *}$ & $450640.528^{* *}$ & $31.590^{\star *}$ & $577.404^{\star *}$ & $35.995^{\star \star}$ & 8 & Genotype \\
\hline 90.392 & 78430.343 & 2.616 & 74.002 & 8.047 & 24 & Err. \\
\hline
\end{tabular}

Table 2- Comparison of morphological characteristics in cotton Genotypes in the second crop (after canola) On 2018-2019. 


\begin{tabular}{|llllll|}
\hline Early maturity & Yield (gr/plot) & Lint percentage & Weight of 30 boll(gr) & No.boll & Varieties \\
& & & & & (Genotype) \\
\hline $34.3 \mathrm{e}$ & $1008 \mathrm{~cd}$ & $38.7 \mathrm{~b}$ & $165.7 \mathrm{a}$ & $18.3 \mathrm{a}$ & SKT133 \\
\hline $91.3 \mathrm{a}$ & $1005 \mathrm{~cd}$ & $32.7 \mathrm{~d}$ & $159.3 \mathrm{~cd}$ & $8.7 \mathrm{bc}$ & GT40 \\
\hline $73.1 \mathrm{bc}$ & $1770 \mathrm{a}$ & $35.9 \mathrm{c}$ & $151.6 \mathrm{de}$ & $11.8 \mathrm{bc}$ & TBL60 \\
\hline $68.6 \mathrm{bcd}$ & $685 \mathrm{~d}$ & $35.8 \mathrm{c}$ & $138.6 \mathrm{e}$ & $12.5 \mathrm{bc}$ & M13 \\
\hline $81.4 \mathrm{ab}$ & $1025 \mathrm{~cd}$ & $39.3 \mathrm{ab}$ & $158.5 \mathrm{~cd}$ & $10.0 \mathrm{bc}$ & K880-1 \\
\hline $82.7 \mathrm{ab}$ & $1013 \mathrm{~cd}$ & $36.1 \mathrm{c}$ & $149.6 \mathrm{de}$ & $8.0 \mathrm{c}$ & K880-2 \\
\hline $72.3 \mathrm{bc}$ & $1143 \mathrm{bcd}$ & $39.8 \mathrm{ab}$ & $162.3 \mathrm{bcd}$ & $12.4 \mathrm{bc}$ & BKW30 \\
\hline $57.2 \mathrm{~d}$ & $1438 \mathrm{abc}$ & $40.1 \mathrm{ab}$ & $174.5 \mathrm{ab}$ & $12.3 \mathrm{bc}$ & Golestan ${ }^{\circ}$ \\
\hline $58.6 \mathrm{~cd}$ & $1538 \mathrm{ab}$ & $41.7 \mathrm{a}$ & $176.3 \mathrm{a}$ & $13.2 \mathrm{~b}$ & N2G80 \\
\hline 13.88 & 408.7 & 2.36 & 12.55 & 4.14 & Duncan $5 \%$ \\
\hline
\end{tabular}

Table 3- Comparison of mean populations of sucking pests in early cultivars in second crop using Duncan $5 \%$

\begin{tabular}{|lll|}
\hline Bemisia tabaci & Aphis gossypii & $\begin{array}{l}\text { Varieties } \\
\text { (Genotype) }\end{array}$ \\
\hline $58.075 \pm 2.101 \mathrm{bc}$ & $27.150 \pm 0.147 \mathrm{c}$ & SKT133 \\
\hline $61.163 \pm 1.840 \mathrm{bc}$ & $39.300 \pm 1.120 \mathrm{ab}$ & GT40 \\
\hline $51.175 \pm 0.457 \mathrm{~cd}$ & $29.112 \pm 0.241 \mathrm{bc}$ & TBL60 \\
\hline $64.300 \pm 1.024 \mathrm{bc}$ & $36.063 \pm 0.187 \mathrm{bc}$ & M13 \\
\hline $65.000 \pm 0.471 \mathrm{bc}$ & $35.125 \pm 0.0126 \mathrm{bc}$ & K880-1 \\
\hline $68.862 \pm 0.364 \mathrm{~b}$ & $48.850 \pm 0.847 \mathrm{a}$ & K880-2 \\
\hline $90.762 \pm 1.804 \mathrm{a}$ & $38.087 \pm 0.238 \mathrm{bc}$ & BKW30 \\
\hline $58.125 \pm 0.114 \mathrm{bc}$ & $46.313 \pm 1.210 \mathrm{a}$ & Golestan ${ }^{8}$ \\
\hline $40.050 \pm 0.527 \mathrm{~d}$ & $31.200 \pm 0.356 \mathrm{bc}$ & N2G80 \\
\hline $16.54 \%$ & $8.8 \%$ & CV \\
\hline
\end{tabular}


Table 4- Correlation between traits in early mature cultivars and sucking pests on second crops.

\begin{tabular}{|llllllll|}
\hline Early mature & yield & White fly & Aphid & Lint.Per. & W.boll & N.boll & vairable \\
\hline & & & & & & 1 & N.boll \\
\hline & & & & & 1 & 0 & W.boll \\
\hline & & & 1 & 0.21 & $0.18-$ & 0 & Aphid \\
\hline 1 & 1 & $0.62-$ & $0.17-$ & $0.08-$ & 0 & White fly \\
\hline 1 & $0.63-$ & 0.50 & $0.180-$ & $0.29-$ & 0 & yield \\
\hline & 0.21 & $0.23-$ & 0.24 & 0.34 & 0.50 & 0.08 & Early mature \\
\hline
\end{tabular}

\section{Discussion:}

Population dynamic of major pests of cotton in the second crop (after canola) on four varieties (43259, 43347, B-557 and Sahel) at Hashem Abad research centers of Gorgan and Kordkoy in 2005-2006. The results show that B-557 and 43259 cultivars compare to the average population of important sucking pests, such as Aphis gossypii (Glov.), Asymmetrasca decdens (Dlabo.), Thrips tabaci(L.) and Bemisia tabaci (G.) Compared to Sahel (check) and other cultivars had less population (Darvish Mojeni, 2010, 2001 and 1988). In researches conducted in Golestan province by Darvish Mojeni and Alishah in 2012, the N2G80, SKT-133, K880-2, TBL-60 and BKW30 cultivars have the least population infestation with important sucking pests such as thrips, aphids, white fly and cotton leafhoppers. Sirjani and Montazeri have been studying on drought tolerant cotton cultivars for Bemisia tabaci cotton in Kashmar in 2012, and Varamin cultivars with an average of .23 .4 nymphs and $11.2 \%$ of adults are in leaf of the highest density and Nazli 84 with a mean of 11.5 nymphs and 8.6 adults had the lowest infestation with white fly. Sirjani and Ramezani Moghaddam studied the difference in infestation of 7 cotton cultivars in Creontides pallidus in Kashmar in 2012. The results showed that 43200 cultivar with an average of 5.03 adults per plant and Irma cultivar with an average of 1.93 adults per plant had the highest and lowest population density counts. Sirjani in 2012 with a study on the comparison of 7 cotton cultivars in terms of infestation with Empoasca decipiens in Kashmar the results showed that cultivar Khordad with the average of 5.56 adults per leaf had the highest infestation and Superokra cultivar with the mean of 2.86 adults per leaf had the least infestation. Therefore, research in Iran is similar with other studies in other countries. (Susa, et al., 1997) researched on the Filipino Research Institute (C R D I) on 30 cotton cultivars and cotton lines for aphid resistant cultivars and reported 5 resistant varieties. Among the remaining cultivars, 17 varieties showed a low resistance, 6 cultivars were sensitive and the remaining two varieties showed high susceptibility to aphid damage. (Kumar and Saini, 2008) examined a number of cotton 
cultivars and lines in Pakistani province for pest resistance morphological characteristics and it came to the conclusion that the earliness in the cultivars makes it possible to escape from the attack on the end of the White fly and bollworm. (Kosas, etal., 2006), studying the preference of cotton aphids on six cotton cultivars in Greece. The results showed that Eva cultivar had a high trichome density on leaf with a population of 58-62 aphids in leaf and Zeta- 2 with the least trichome density on the leaf population of aphid, 29-33 aphids per leaf had the lowest aphid population. Therefore, the cultivars bearing N2G80, TBL-60 and SKT-133 in this project had the lowest population of infestation with important sucking pests (thrips, aphids and whitefly ) and, on the other hand, they had a good yield and early maturity, which could be used in the future for the release of new Varity or in the production of new hybrids. The genotypes NHH44, LK861, Supriya, RS2013 and LD694 were categorized as moderately resistant in cotton to whitefly.(Jindal and Dhaliwal,2011)

\section{Conclusion:}

The genotype N2G80 had the lowest whitefly population density of 40.1 per leaf tolerant group and genotype BKW30 had the highest whitefly population density of 90.8 per leaf sensitive group. The genotype SKT133 had the lowest aphid population density of 27.2 per leaf tolerant group and genotype K880-2 had the highest population density of 48.9 per leaf sensitive group.

\section{Declarations:}

\section{Acknowledgments}

The authors would like to thank Cotton Research Institute of Iran.

\section{Authors' contributions}

Mojeni,T.D. determined the population density of sucking pests on cotton genotypes and wrote the article.. Zangi, M. They prepared and cultured the genotypes at the research station.

\section{Funding}

This work was supported by Cotton Research Institute of Iran.

\section{Availability of data and materials}

Not applicable.

\section{Ethics approval and consent to participate}

Not applicable.

\section{Consent for publication}


Not applicable.

\section{Competing interests}

Authors declare that they have no conflict of interest for the publication of the manuscript.

\section{Author details}

1,2-Cotton Research Institute of Iran, Agricultural Research, Education and Extension Organization (AREEO), Gorgan, Iran.

\section{References:}

1-Abaei, M., Darvish, Mojeni,T. 1994. Investigating the infestation rate of different varieties of cotton to whitefly. Agriculture Research Center Gorgan and Gonbad.P: 22-29.

2-Darvish, Mojeni,T. 1996. Final report on identification of cotton aphids and their dominant species in Gorgan and Gonbad. Agriculture Research Center Gorgan and Gonbad. 35 p.

3-Darvish, Mojeni,T.,Taziki,A. 1998. Final Report on infestation of different varieties of Cotton to Aphis Gossypii. Agriculture Research Center Gorgan and Gonbad, Number, 143/77. 33 p.

4-Darvish, Mojeni,T. 2000. Study of important Pests in Cotton Introduction. Cotton Research Institute of Gorgan, P:171-186.

5-Darvish, Mojeni,T., Alisha, 0.2006 . Final report investigation of the infestation different cotton cultivars to Liriomyza trifolli in the Golestan province. Cotton Research Institute of Iran . Number, 340/84. 11p.

6-Darvish, Mojeni,T.2010. Study of population dynamic of major cotton pests in second culture (after canola) with conventional culture. Cotton Research Institute of Iran. Number.299 / 88. 14 p.

7-Darvish, Mojeni,T., Alisha, O. 2013. Final report study on infestation of successful lines to the population of important cotton sucking pests. Cotton Research Institute of Iran. Number, 40745. 41 p.

8-Darvish, Mojeni,T.2011. Final report study on infestation of new cotton hybrids to important sucking pests. Cotton Research Institute of Iran. Number, 44607. 30 p.

9-Gao , Z . R . 1989 . A study of Aphis gossypii in cotton at different stage . Plant protection . 13 (4 ) p: 810.

10- Khan,Z.R. , Agarwal,R.A. 1990. Mechanism of resistance to aphid ( Aphis gossypii) in cotton. Indian Journal of Entomology,52(2),P.236-240.

11-Kostas,D.Z.,Margaritopoulos,J.T.,Stathi,L.,Tsitsipis,J.A.2006.Performance of cotton aphid Aphis gossypii(Hemiptera: Aphidiae) lineages on cotton varieties.International Journal of pest 
Management.52(3):225-232.

12-Kumar, S. , Saini, R.K.2008. Feeding Preference and Damage Potential of Helicoverpaarmigera(Hübner)on different Promising Cotton Genotypes/Hybrid.J.Agri.Sci.Tech.Vol.10: 411-420.

13- Jindal,V.ana Dhaliwal, G.S.2011.Mechanisms of resistance in cotton to whitefly (Bemisia tabaci):Antixenosis.Phytoparasitica 39(2):129-136.

14- Nantihalli , B. S; Patil , B. V. , Lingappa , S. 1993 . Population dynamic of cotton whitefly Bemisia tabaci (Genn. ) . Kamataka . J . Agric. Sci. 6 ( 1 ) p : 25- 29.

15- Li , C , Li , S. Q , Guo , B. F. 1987. Studies on the temperature threshold of cotton bollwrom development in vaning temperature enviroments. Acta. Entomol. Sinica, 30 ( 3) p: 257- 258.

16-Sirjani, M., Ramezani, Moghadam.M.2013. Investigation on the difference of infestation of 7 Cotton Cultivars with Creonides Pallidus in Kashmar.The $1^{\text {St }}$ International Conference on Science, Industry and Trade of Cotton Gorgan of Iran.P:211.

17-Sirjani, M.2013. Comparison of 7 cotton cultivars in terms of infestation to Emposasca decipiens in Kashmar. The $1^{\text {St }}$ International Conference on Science, Industry and Trade of Cotton Gorgan of Iran.P:212.

18-Sirjani, M., Montazeri,M. 2013. Comparison of land tolerant cotton cultivars in terms of whitefly of Bemisia tabaci in Kashmar. The $1^{\text {St }}$ International Conference on Science, Industry and Trade of Cotton Gorgan of Iran.P:210.

19- Susa, A. M., Paraoan, I. R.,Castillo, F.S., Rinen, E. C.1997. Screening of cotton varieties/lines for aphids, Aphis gossypii Glover, resistance. Philippine J. of Crop Science. 22(1): 4.

20-Tamilselvan,R.,Mahalingam,C.A.,Mohankumar,S.andSenguttuvan,K.2020.Characterizaton of resistance mechanisms to the whitefly Bemesia tabaci Asia - II-8 (Hemiptera: Aleyrodidae) in cotton genotypes.International Journal of tropical Insect Science 41(1):373-381.

\section{Figures}




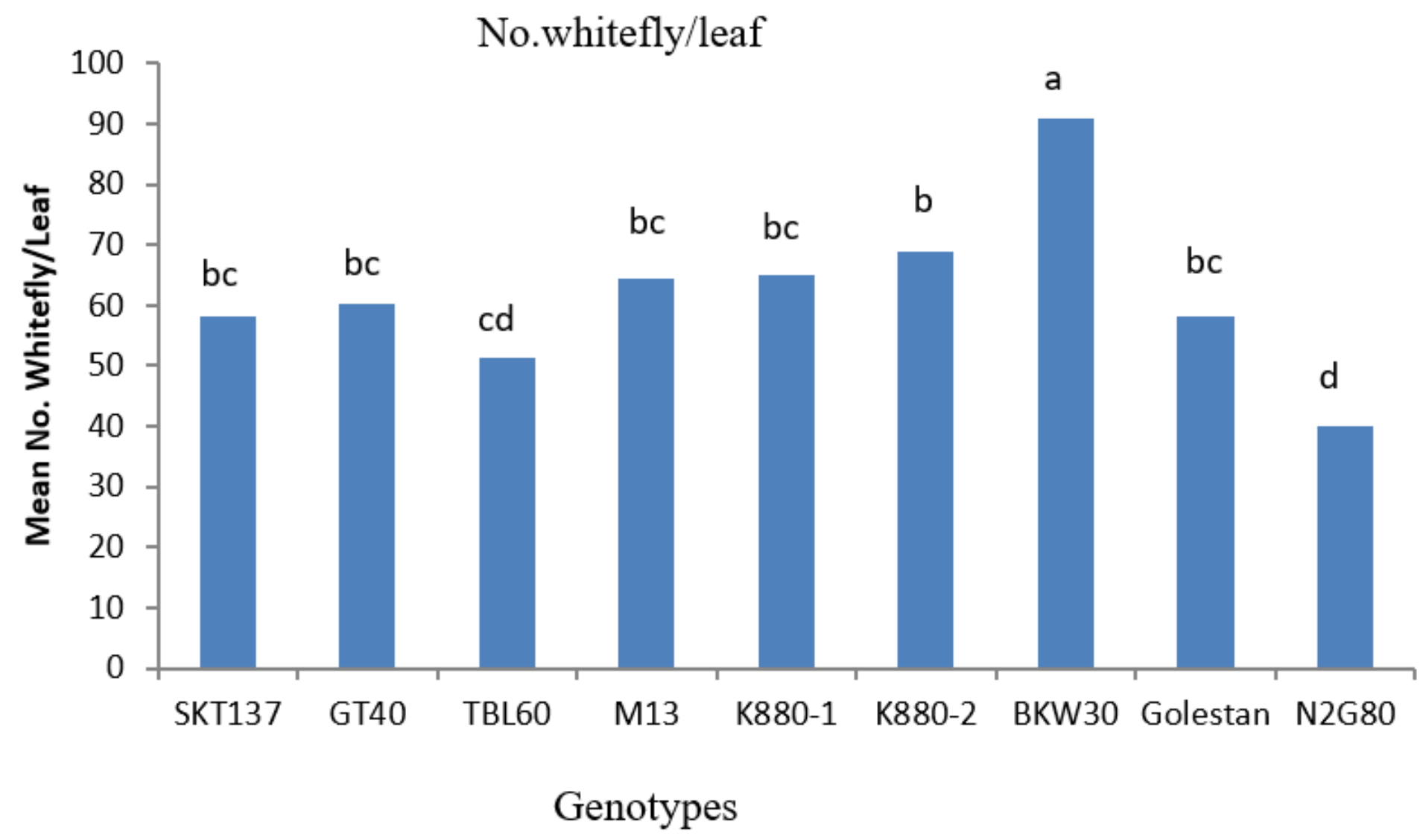

Figure 1

Population dynamic of Bemisia tabaci (G.) on Genotypes 


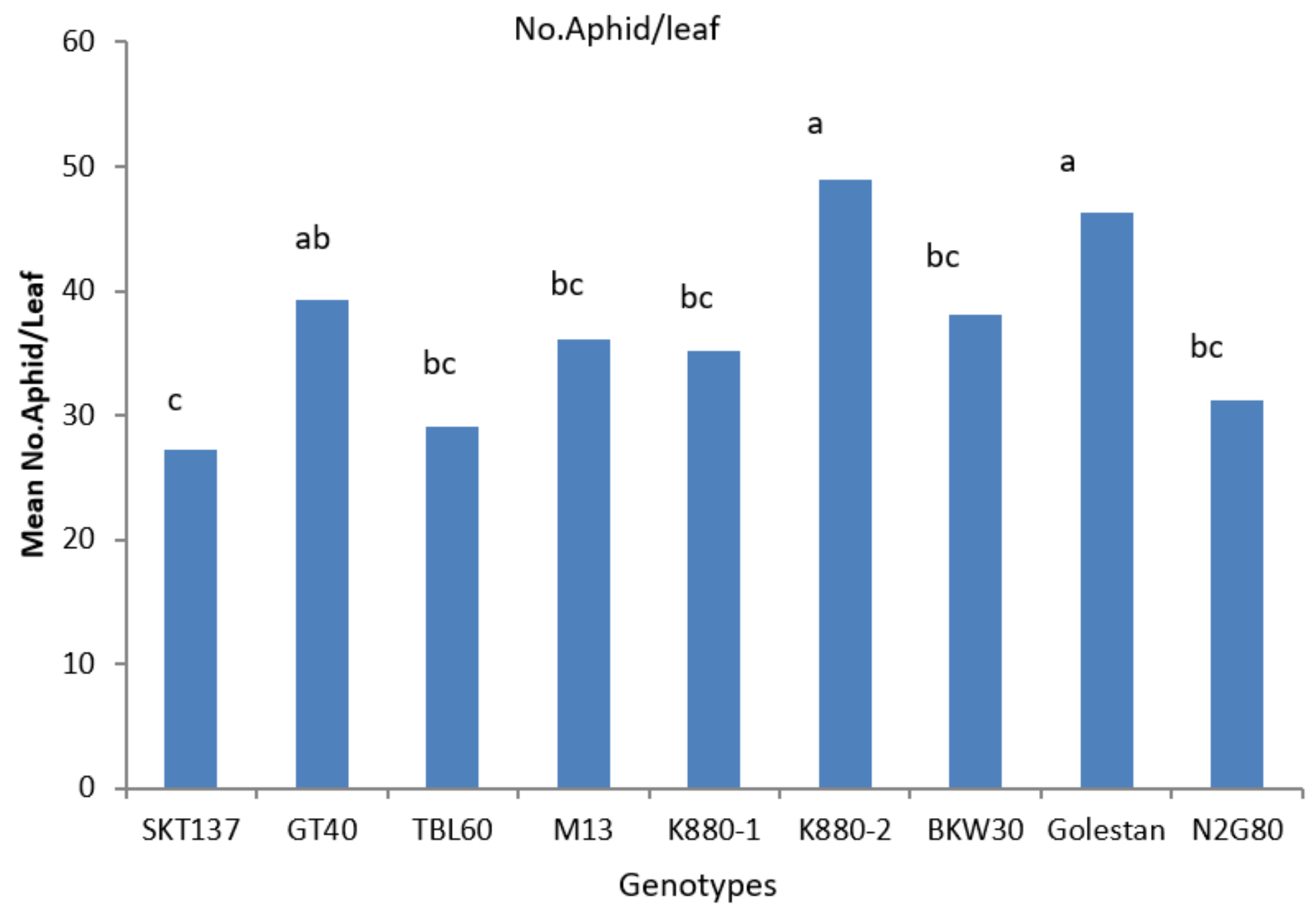

Figure 2

Population dynamic of Ahis gossypii (Glove.) on Genotypes 